\title{
Differentiation of Streptomyces coelicolor A3(2) under nitrate-limited conditions
}

\author{
Atul Karandikar, George P. Sharples and Glyn Hobbs \\ Author for correspondence: Glyn Hobbs. Tel: +44 151231 2198. Fax: +44 1512074726. \\ e-mail: g.hobbs@livjm.ac.uk
}

School of Biomolecular Sciences, Liverpool John Moores University, Byrom Street, Liverpool L3 3AF, UK

\begin{abstract}
The life cycle of Streptomyces coelicolor during development on solid medium has been studied from a physiological perspective. A biphasic growth pattern was demonstrated, evidenced by a continuous transition from an initial exponential growth period into a slower phase of biomass accretion. The switch between the two phases coincided with the exhaustion of nitrate from the medium. The depletion of nitrate from the medium coincided with the initiation of aerial mycelium formation within the cultures and the development of hydrophobic surface properties. During secondary growth, cultures remained metabolically active, continuing to accumulate DNA, despite a cessation in the levels of RNA and cell protein accretion. In addition, the accumulation of glycogen and lipid contributed to the observed accretion of biomass in this phase. The depletion of nitrate also marked an increase in the production of $\alpha$-ketoglutarate by the culture and a coincident decrease in medium pH. Latter stages of the secondary growth phase saw the development of spores within the culture, this in turn was associated with a decrease in cellular glycogen. This supported previous observations that glycogen degradation and spore maturation were intimately associated.
\end{abstract}

Keywords: nitrate limitation, Streptomyces coelicolor, macromolecules, storage compounds, differentiation

\section{INTRODUCTION}

Streptomycetes exhibit a complex developmental cycle that involves a number of physiologically distinct stages including spore germination, vegetative hyphal growth, the production of aerial hyphae and sporulation (Hodgson, 1992). The life cycle has been most extensively studied in Streptomyces coelicolor and a range of developmental mutants have been isolated that are blocked at various stages of differentiation (Champness $\&$ Chater 1994). These mutants have enabled many of the genes involved in the developmental pathway to be cloned and studied at the molecular level.

In contrast, the physiology of the process has received far less attention. The reason for this is that the expression of the developmental cycle, as a whole, only occurs on surface cultures which are not particularly amenable to physiological studies. Streptomycetes can be induced to sporulate in submerged liquid culture following nutrient downshift (Kendrick \& Ensign, 1983; Koepsel \& Ensign, 1984; Huber et al., 1987; Daza et al., 1989; Glazebrook et al., 1990). The sporulation process under these conditions does not appear to involve a stage corresponding to aerial mycelium formation. In addition, spores produced in submerged culture have different properties to spores formed on solid media (Koepsel \& Ensign, 1984). As noted by Kalakoutskii \& Agre (1976), it is difficult to draw parallels between the developmental cycle on solid substrates and in liquid culture when the patterns of morphological development are incomparable. The majority of genetic studies have been conducted using surface cultures: it is therefore desirable to focus on physiological studies under similar growth conditions. Consequently, the development of a system employing membrane cultures by Shahab et al. (1994) has provided a means by which the life cycle can be entirely expressed while enabling growth, product formation and substrate consumption to be readily monitored. This approach has allowed us to define nutrient conditions that support the complete differentiation process of the organism (Karandikar et al., 1996). Stoichiometric limitation of growth by nitrate in the medium was one of the prerequisites for sporulation in these conditions. Here we report a detailed physiological profile of the organism's development 
throughout the cycle, showing the relationship between nitrate depletion and the differentiation process.

\section{METHODS}

Organism. S. coelicolor A3(2) strain 1147 (Hopwood, 1959) was used throughout this study.

Media, inoculum and culture conditions. The culture conditions used during the study were based on those previously described by Karandikar et al. (1996). The minimal medium consisted of $\left(\mathrm{g}^{-1}\right)$ : glucose, $50 ; \mathrm{NaNO}_{3}, 1 \cdot 7 ; \mathrm{K}_{2} \mathrm{HPO}_{4}, 1 ; \mathrm{KCl}$, $0.5 ; \mathrm{Mg}_{2} \mathrm{SO}_{4} .7 \mathrm{H}_{2} \mathrm{O}, 0.5 ; \mathrm{Fe}_{2} \mathrm{SO}_{4} .7 \mathrm{H}_{2} \mathrm{O}, 0.01$. The medium was supplemented with $2.5 \mathrm{~g} \mathrm{l}^{-1}$ trace-salts solution (Hobbs $e t$ al., 1989), solidified with Oxoid Agar no. $3\left(15 \mathrm{~g} \mathrm{l}^{-1}\right)$ and aliquots $(25 \mathrm{ml})$ poured into each Petri dish $(90 \mathrm{~mm})$. Spores $\left(1 \times 10^{9}\right.$ per plate) were inoculated onto the surface of sterile cellophane membrane discs (Courtalds) which had previously been overlaid onto the solidified medium. Spores were spread confluently and 30 plates incubated at $30^{\circ} \mathrm{C}$ in each aerated growth chamber $(4 \cdot 0 \mathrm{l})$. The inlet air was passed through a soda lime column to remove carbon dioxide and air was drawn through the chamber at a flow rate of $0.25 \mathrm{ml} \mathrm{min}$.

Sampling and analytical procedures. Gas analysis was conducted using an IR gas analyser (MSA) connected to the outlet of one of the growth chambers, which was used exclusively for monitoring $\mathrm{CO}_{2}$ evolution. Sampling of plates for analysis of substrates, non-gaseous products and biomass was sacrificial, with five plates being removed from identical chambers at each time point. Liquid samples for the analysis of products and substrates were prepared from agar plugs taken from beneath the membranes as previously described (Shahab et al., 1994).

Biomass was determined by scraping the cell material from the surface of the membrane with a razor blade. The cell material was then placed on the surface of a preweighed GF/A filter (Whatman) and washed with $30 \mathrm{ml}$ distilled water. The material was then dried to a constant weight in a microwave oven and dry weights calculated from the difference in weight.

Glucose and nitrate were measured using enzyme-based test kits (Boehringer Mannheim). Phosphorus was determined by the procedure of Plummer (1987). Protein was measured by the method of Bradford (1976) using a dye-based test kit (Bio$\mathrm{Rad}$ ). Cellular macromolecules were extracted and analysed as previously described (Shahab et al., 1996), except that protein was measured as described above. Total lipid was extracted from powdered, freeze-dried cells by extraction with chloroform/methanol $(2: 1, \mathrm{v} / \mathrm{v})$ as described by Folch $e t$ al. (1957). The amount of lipid was determined gravimetrically by drying the extract to constant weight in preweighed tubes using a rotary solvent evaporator (GYROVAP; Howe).

To prepare cell extracts for measuring intracellular carbohydrates, mycelia were suspended in $10 \mathrm{mM}$ potassium phosphate buffer $(\mathrm{pH} 7.0)$ and disrupted by sonication for $6 \times 1 \mathrm{~min}$ pulses using the exponential probe of a Soniprep 150 sonicator (MSE). Glycogen and trehalose were measured as previously described by Braña et al. (1982) and McBride \& Ensign (1987a), respectively.

Hydrophobicity was determined from contact angle measurements. Drops $(10 \mu \mathrm{l})$ of distilled water were placed on the surface of the culture and immediately photographed from a horizontal perspective. Measurements were then taken from the photographs.

Extracellular levels of pyruvate and $\alpha$-ketoglutarate were measured by HPLC after identification by comparison with authentic standards. Samples of culture supernatant were filtered through 0.2 $\mu \mathrm{m} \mathrm{Z}$-spin micro-filters (Gelman Sciences). Aliquots $(20 \mu \mathrm{l})$ were loaded onto an ODS2 S5 reverse-phase column (Spherisorb; Waters) and eluted with $0.1 \mathrm{M}$ sodium sulphate ( $\mathrm{pH} \mathrm{2.47)}$ at a flow rate of $1 \mathrm{ml} \mathrm{min} \mathrm{m}^{-1}$. Organic acids were detected by their $A_{210}$ spectra (Bio-Rad model $1801 \mathrm{UV}$ Monitor).

Scanning electron microscopy. Representative samples of growth on cellophane membranes $(5 \times 5 \mathrm{~mm})$ were cut from the centres of the agar plates using a razor blade. Samples were then prepared for scanning electron microscopy in a Hexland Cryo System (Oxford Instruments). Samples were observed with a JSM 840 (JEOL) scanning electron microscope.

\section{RESULTS}

\section{Membrane culture growth dynamics}

Membrane cultures, grown on the nitrate-limited medium, exhibited a biphasic growth pattern. A lag phase of $20 \mathrm{~h}$ duration was followed by a rapid growth phase over the period $20-70 \mathrm{~h}$ post-inoculation (Fig. 1a). Termination of the rapid growth phase coincided with depletion of nitrate from the medium which was completely exhausted at $75 \mathrm{~h}$. This initial phase of growth was then followed by a slower period of biomass accretion. The semi-logarithmic plot of biomass versus time indicated that the primary growth phase was exponential (Fig. 1b), with a mean growth rate of $0 \cdot 15 \mathrm{~h}^{-1}$ during the mid-exponential phase. The growth rate then declined rapidly, $60 \mathrm{~h}$ post-inoculation, with biomass accretion eventually ceasing after $135 \mathrm{~h}$. Glucose consumption was most pronounced during the primary growth phase but subsequently this nutrient continued to be depleted from the medium to a significant extent (Fig. 1c). Agarolytic activity (assessed by Gran's test as described by Hodgson \& Chater, 1981) and cellulolytic activity (based on microscopic examination of cellophane membranes) could not be detected, confirming that glucose was the sole exogenous source of carbon. The production of carbon dioxide by the cultures mirrored the biomass accretion throughout the primary growth phase, reaching a maximum at the end of this period and declining steadily once nitrate had become exhausted from the medium. The $\mathrm{pH}$ of the medium was also found to change throughout the growth phases of the organism (Fig. 1d). The initial rapid phase of growth was accompanied by a marked rise in $\mathrm{pH}$ to 9.5 , followed by acidification of the medium which began before nitrate was depleted. This decrease in $\mathrm{pH}$ coincided with a decline in growth rate. This may have been a response by the organism to nutrient limitation either as a result of a decreasing concentration of medium nitrate or diffusion limitation into the mycelial mass. The decrease in $\mathrm{pH}$ suggested the appearance of organic acids in the medium which are known to be common overflow metabolites produced by this organism (Hobbs et al., 1992). Pyruvate and $\alpha$ ketoglutarate as organic acid products were identified in the medium (Fig. 1e). Pyruvate was the major species of acid excreted during the primary growth phase. Levels 
(a)

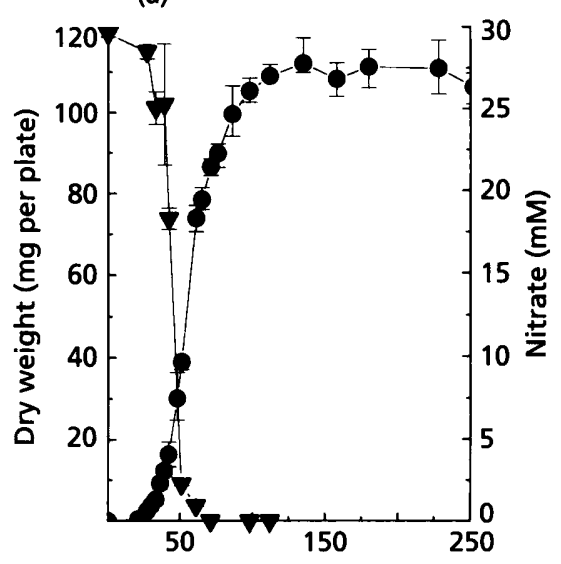

(d)

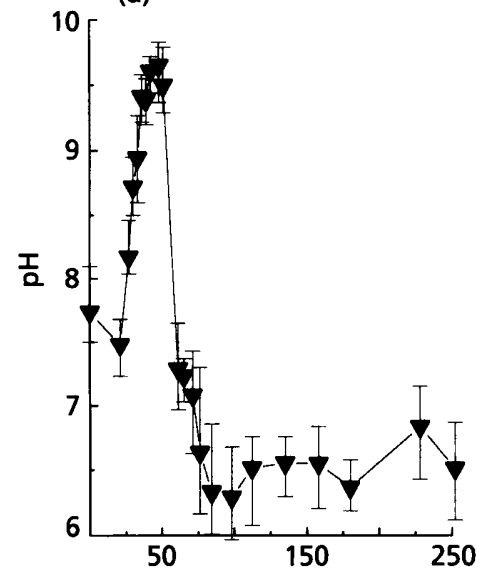

(b)

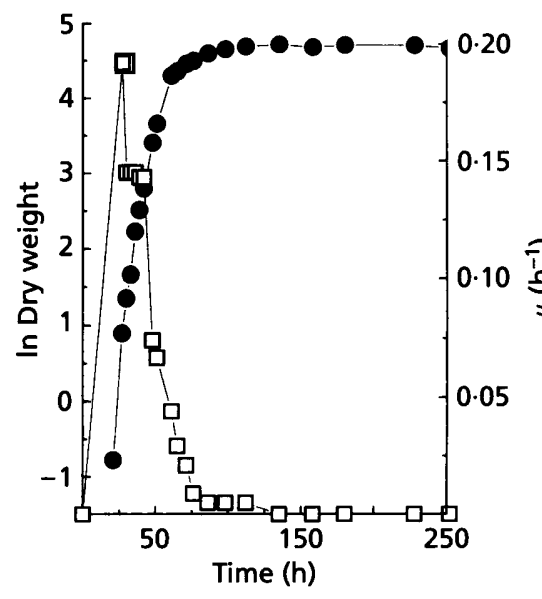

(e)

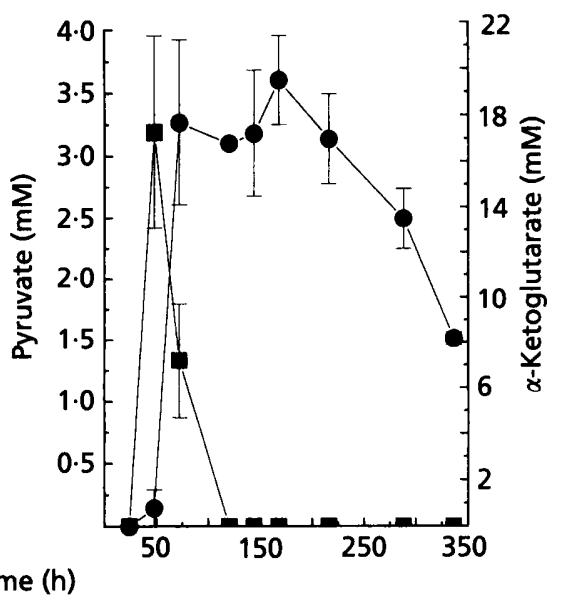

(c)

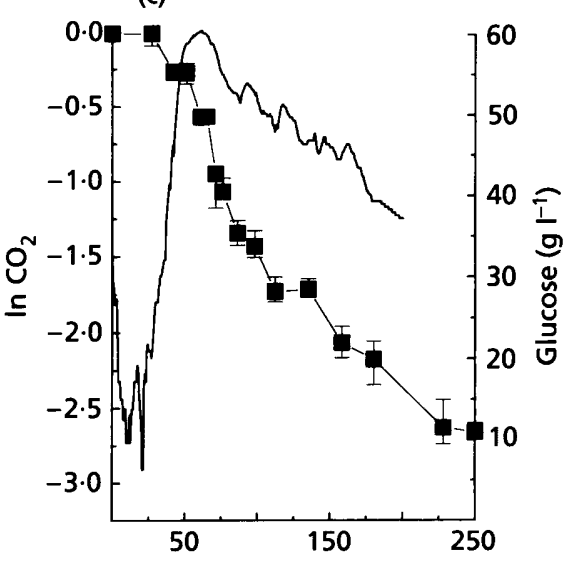

Fig. 1. Growth, nutrient utilization and acid production under nitrate-limited conditions. (a) Dry weight biomass (O) and residual nitrate $(\nabla)$. (b) Natural logarithm of dry weight $(\bullet)$ and specific growth rate, $\mu(\square)$. (c) Natural logarithm of $\mathrm{CO}_{2}$ evolution ( $\longrightarrow$ ) and residual glucose $(\boldsymbol{D})$. (d) $\mathrm{pH}(\boldsymbol{\nabla})$. (e) Pyruvate $(\boldsymbol{\square})$ and $\alpha$-ketoglutarate $(\boldsymbol{O})$. Values shown are the mean of five determinations. Error bars represent the range of values obtained. $\mathrm{CO}_{2}$ data show values for a typical batch run.

of this acid declined following nitrate depletion. In contrast, $\alpha$-ketoglutarate was produced maximally during the secondary growth phase and declined $170 \mathrm{~h}$ postinoculation. These results clearly demonstrate that the culture environment changed markedly throughout the period of culture growth and that the onset of nitrate limitation initiated profound changes in culture growth rate, metabolism, nutrient uptake and medium $\mathrm{pH}$.

\section{Kinetics of macromolecule accumulation in plate cultures}

To determine whether the secondary phase of biomass accretion was associated with continued cellular proliferation or simply due to accumulation of storage products, the levels of the cellular macromolecules (DNA, RNA and protein) were monitored. The total amount of DNA per plate was found to increase rapidly during the initial growth phase coincident with the increase in biomass (Fig. 2a). Following nitrate depletion, DNA accumulation continued, consistent with sustained cellular proliferation. The DNA concentration per plate reached a maximum at $145 \mathrm{~h}$, following which the levels declined slightly, finally rising again after $290 \mathrm{~h}$. The level of RNA increased throughout the rapid growth phase (Fig. 2b). At the point of nitrate depletion, RNA levels decreased steadily up to $250 \mathrm{~h}$ following which there was a marked increase in RNA synthesis up to $300 \mathrm{~h}$. Total protein production followed a similar pattern of increase during the initial growth phase, continuing to accumulate following nitrate depletion up to $96 \mathrm{~h}$, beyond which no further increase in level was measured (Fig. 2c). These results suggest that the secondary phase of biomass accretion is at least in part due to continued cell replication. The increase in total macromolecules, however, does not account for the 
(a)

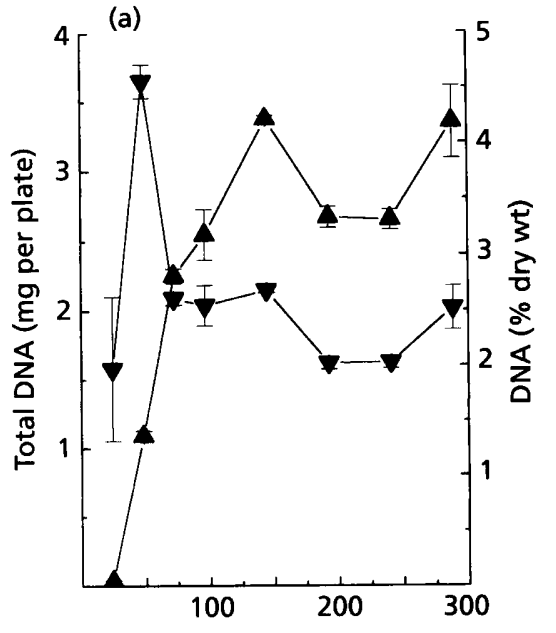

(b)

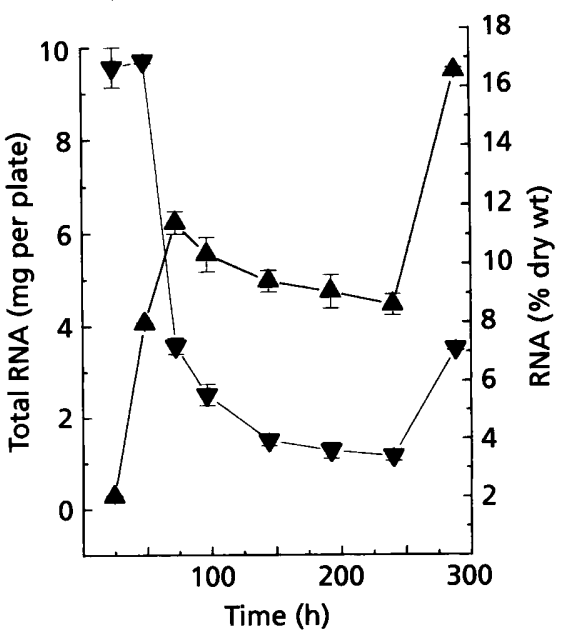

(c)

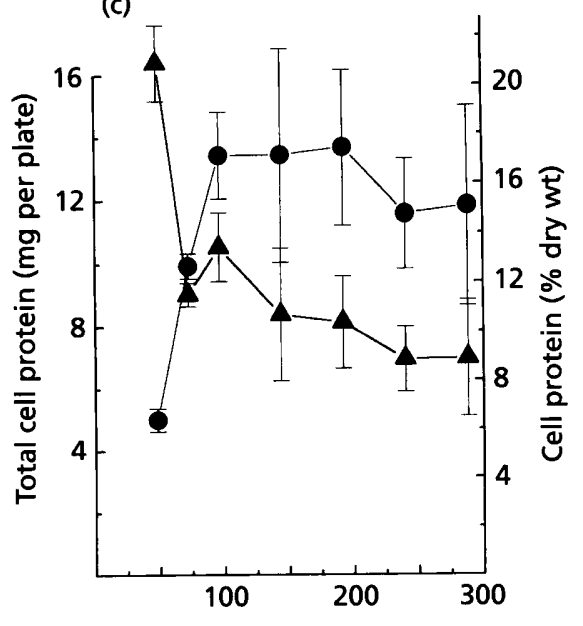

Fig. 2. Accumulation of cell macromolecules. (a) Total DNA ( $\mathbf{A})$ and percentage DNA of the dry weight ( $\boldsymbol{\nabla})$. (b) Total RNA $(\boldsymbol{\Lambda})$ and \% RNA of the dry weight $(\boldsymbol{\nabla})$. (c) Total protein $(\boldsymbol{O})$ and percentage protein of the dry weight $(\boldsymbol{\Delta})$. Values shown are the mean of five determinations. Error bars represent the standard errors.

total increase in biomass that is seen in the second growth phase. The possibility therefore remained that the exponential growth phase was followed by a period of slower cell proliferation, during which biomass accretion was partially attributed to accumulation of cellular storage material.

\section{Changes in carbohydrate content during culture growth}

Under conditions of nitrogen exhaustion, a striking characteristic of many bacteria is their ability to accumulate significant quantities of reserve carbonaceous compounds (Wanner \& Egli, 1990). The major storage compounds reported to be synthesized by streptomycetes are glycogen (Braña et al., 1982; Ranade \& Vining, 1992; Plaskitt \& Chater, 1995) and trehalose (Elbein, 1967).

During growth of surface cultures, glycogen was exclusively accumulated following the exhaustion of nitrate from the medium (Fig. 3a), reaching a maximum, $190 \mathrm{~h}$ post-inoculation. The level of glycogen declined in cultures beyond the $190 \mathrm{~h}$ time point, indicating degradation of this storage material. This was unexpected considering that the medium glucose had not been depleted at this stage and that glycogen degradation normally occurs under conditions of carbon limitation (Preiss \& Romeo, 1989). However, this may reflect cellular compartmentalization in this organism and the physical separation of the aerial growth from the substrate (Plaskitt \& Chater, 1995).

In contrast to glycogen, trehalose appeared to be accumulated during the primary growth phase (Fig. 3a), becoming depleted as nitrate concentrations in the medium diminished. Trehalose reached a steady-state level of approximately $2 \%(\mathrm{w} / \mathrm{w}) 75 \mathrm{~h}$ post-inoculation, throughout the remainder of the study (Fig. 3b). Clearly the increasing levels of biomass in the secondary period of growth cannot be accounted for by the storage of glycogen and trehalose alone. Trehalose was only accumulated maximally during the rapid growth phase, representing $13 \%(\mathrm{w} / \mathrm{w})$ of the mycelial mass (Fig. $3 \mathrm{~b}$ ). Although glycogen was exclusively synthesized during the secondary growth phase, levels only reached a maximum $6 \%(\mathrm{w} / \mathrm{w})$ of the total cell biomass.

\section{Hydrophobicity and lipid accumulation}

It was observed that a dramatic change in the hydrophobicity of this organism occurs when undergoing differentiation on complex media, consistent with the hydrophobic nature of streptomycete spores reported previously (Ruddick \& Williams, 1972; Ensign, 1978). A temporal study quantifying the hydrophobic nature of the surface cultures throughout the growth cycle was conducted. During the primary phase of growth, cultures were ostensibly wettable, displaying no hydrophobic characteristics (Fig. 4). At the point of nitrogen depletion, there was a marked increase in hydrophobicity, reaching a maximum contact angle of $110^{\circ}$ after $145 \mathrm{~h}$. It was clearly seen that surface hydrophobicity was closely associated with the secondary phase of growth. Nutrient limitation was previously shown in the yeast Saccharomyces cerevisiae to be a major determinant of cell surface hydrophobicity (Smit et al., 1992). It is therefore likely that nutrient exhaustion is the key trigger for this major physical change in $S$. coelicolor. The possibility that the hydrophobic nature of the cultures may be due to lipid accumulation was then examined. The lipid content of the biomass was found to increase with culture age, accumulating signi- 


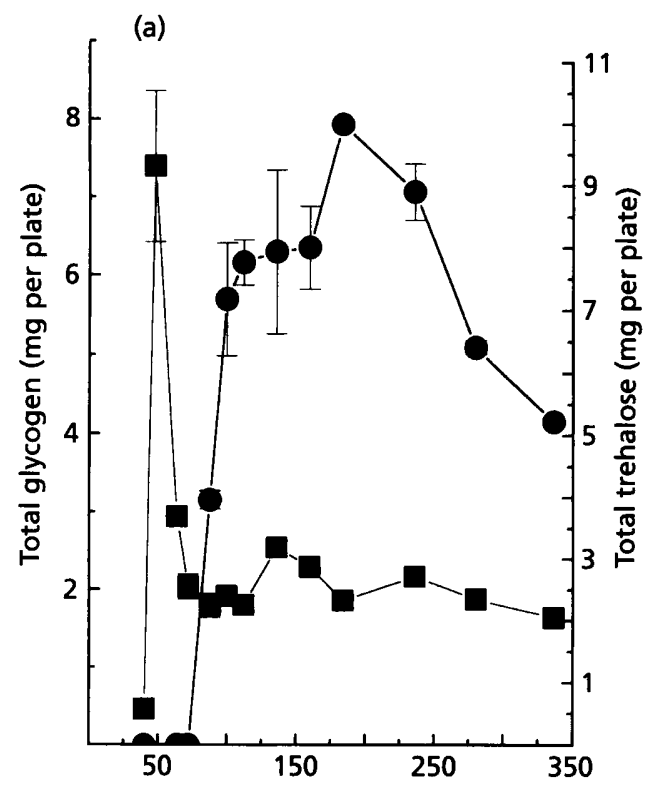

(b)

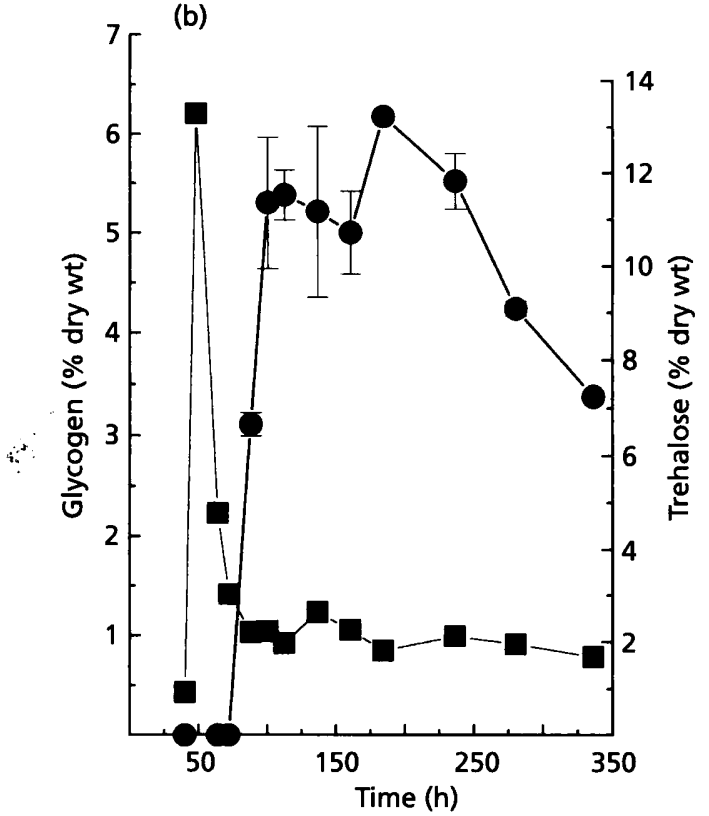

Fig. 3. Accumulation of intracellular carbohydrates. (a) Total cellular glycogen (O) and trehalose (D). (b) Percentage glycogen of the dry weight (O) and percentage trehalose of the dry weight ( $\square$ ). Values shown are the mean of five determinations. Error bars represent the standard errors.

ficantly towards the end of the primary growth phase as the nitrate levels declined (Fig. 5). Lipid contributed $20 \%(\mathrm{w} / \mathrm{w})$ of the total cell mass $75 \mathrm{~h}$ post-inoculation, a level that was largely sustained throughout the secondary growth phase. Clearly, lipid represented a major constituent of the culture mycelial mass. Significant cellular lipid accumulation and an increase in surface hydrophobicity both followed nitrogen exhaustion.

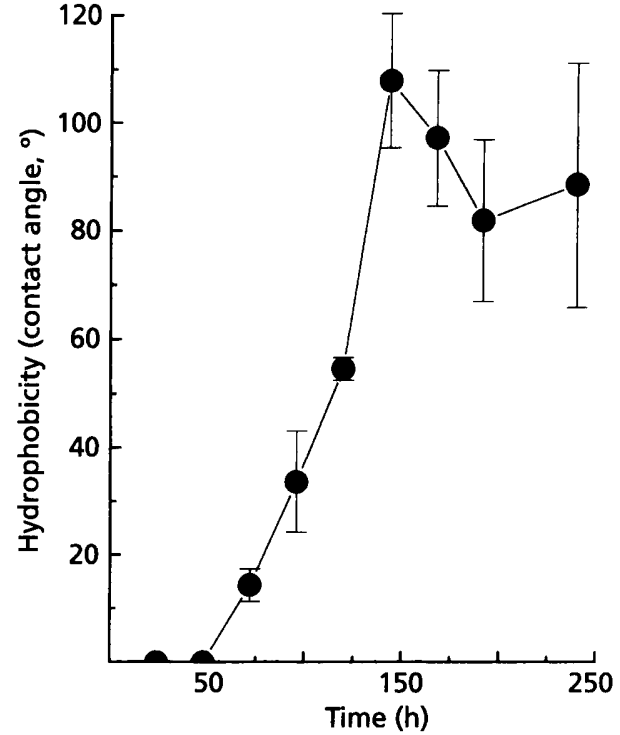

Fig. 4. Culture surface hydrophobicity determined by contact angle (O). Values shown are the mean of five determinations. Error bars represent the range of values obtained.

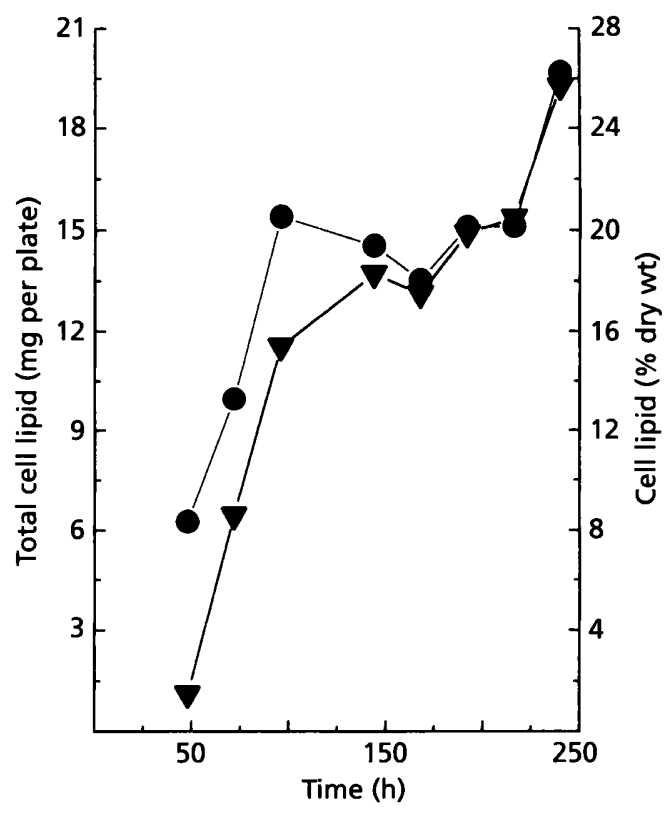

Fig. 5. Total cellular lipids (O) and percentage lipids of the dry weight $(\boldsymbol{\nabla})$. For each sample point, the biomass from five plates was pooled and the data represent the mean lipid content per plate.

\section{Morphological development and associated physiological changes}

The correlation between the physiological changes described and the developmental cycle of the organism was examined. Morphologically, a distinct temporal 

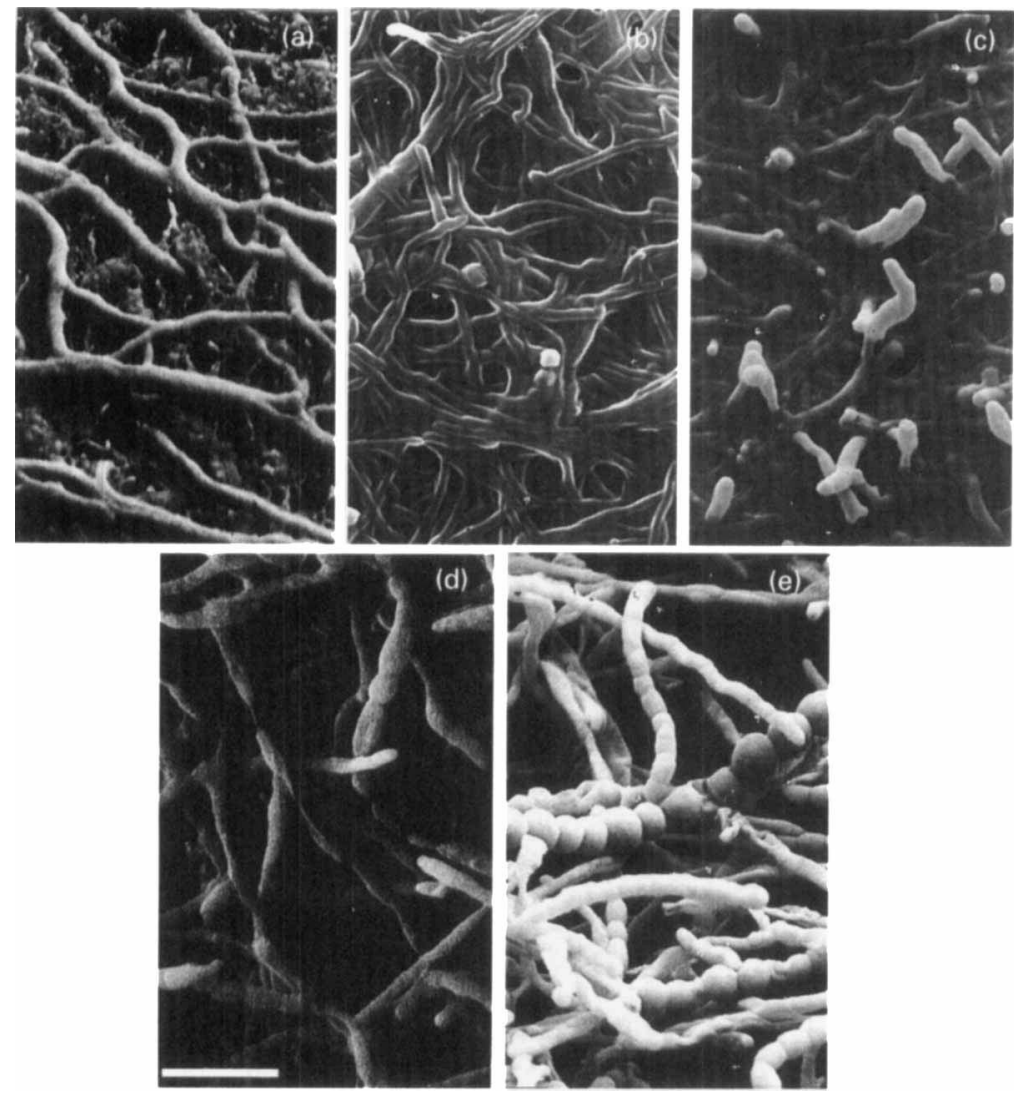

Fig. 6. Scanning electron micrographs showing the temporal profile of growth on membrane cultures at selected time points under nitrate-limited conditions. (a) Outgrowth and branching of substrate hyphae after $24 \mathrm{~h}$. (b) Formation of a dense network of interwoven and convoluted substrate hyphae, $48 \mathrm{~h}$ post-inoculation. (c) Initial emergence of aerial hyphae $75 \mathrm{~h}$ postinoculation. (d) Aerial hyphal growth $120 \mathrm{~h}$ post-inoculation. (e) Formation of spores $145 \mathrm{~h}$ post-inoculation. Bar, $5 \mu \mathrm{m}$.

pattern of development was recognized as shown in Fig. 6 . The first $24 \mathrm{~h}$ incubation period was characterized by the outgrowth and subsequent branching of prostrate substrate hyphae (Fig. 6a). Forty-eight hours postinoculation, growth was seen as a dense network of interwoven and convoluted hyphae (Fig. 6b), as previously described by Hopwood (1960). This initial vegetative phase was associated with rapid biomass accretion and culminated in the depletion of medium nitrate. At $75 \mathrm{~h}$, coincident with nitrogen depletion, the prostrate hyphae could be seen to have formed an indistinct mycelial mat from which the emergence of aerial hyphae was observed (Fig. 6c). This morphologically distinct stage of development was characterized by a marked increase in surface hydrophobicity. It therefore appeared that hydrophobicity could be regarded as a developmental marker indicative of aerial growth in this organism. A similar correlation had been reported between aerial hyphae and hydrophobicity in the fungus Schizophyllum commune (Wessels et al., 1991). The appearance of aerial growth also corresponded with several physiological changes including significant accumulation of glycogen and lipid along with a marked decrease in metabolic activity (indicated by a decrease in $\mathrm{CO}_{2}$ evolution). This period of sustained aerial growth coincided with continued accumulation of DNA, but a cessation in RNA and protein accumulation. By $120 \mathrm{~h}$, the aerial mycelia had formed a dense body of hyphae with evidence of septation in some hyphae
(Fig. 6d). The final stage of development was identified by the appearance of discrete spore chains after $145 \mathrm{~h}$ (Fig. 6e). Apart from the cessation of biomass accretion, the distinct formation of spores was not identified by any other recognized physiological events. However, as sporulation proceeded, glycogen accumulation stopped after $190 \mathrm{~h}$ and the levels of the polysaccharide began to decrease significantly.

\section{DISCUSSION}

Membrane cultures provide a convenient method for studying streptomycete differentiation. Significantly, they provide a reproducible and predictable means by which physiological investigations can be conducted while allowing the organism to express all stages of its growth cycle.

The growth pattern reported exhibits an initial exponential growth phase that agrees with the model of Pirt (1975) for growth of bacterial colonies. The subsequent decrease in growth rate towards the end of the exponential period coincided with the depletion of the limiting nutrient in the medium. This is in accord with the growth kinetics predicted by Monod (1942) for an organism growing in the presence of a single limiting nutrient. Therefore, the organism has a growth pattern which follows well-established models for growth kinetics, behaving in a way that can be predicted by these accepted rules. This contrasts with previous 
reports of Allan \& Prosser (1985) who suggested that surface growth is limited by the production of staling compounds by the organism. It is likely that this phenomenon reflected the different nutritional conditions employed by these workers.

Biphasic growth is commonly reported for a wide range of organisms growing in conditions of nitrogen limitation (Wanner \& Egli, 1990; Harder \& Dijkhuizen, 1983). Previous work on membrane cultures by Granozzi et al. (1990) also reported a biphasic growth pattern, however the nature of the limiting nutrient was not reported. These authors established a relationship between the transition between the two phases of growth and a transient cessation of growth, a phenomenon that was believed to be important in initiating differentiation in this organism. In contrast, at no stage during our studies did we find such a transient cessation of growth as biomass accretion was continuous during the shift between phases. The results from a previous study (Karandikar et al., 1996) suggested that the physiological stress responsible for the switch to the secondary growth phase was a result of nitrogen exhaustion. Furthermore, there appeared to be an intimate link between nitrate exhaustion and initiation of aerial hyphae formation. This link was further supported by the work of Braña et al. (1986) who demonstrated a direct relationship between a reduction in medium nitrogen concentration and the onset of aerial growth in Streptomyces antibioticus. It was impossible to dissociate growth rate effects from those resulting from nutrient limitation using our present system. However, the fact that the formation of aerial mycelia was not initiated under conditions limited for either phosphate (data not published) or glucose (Karandikar et al., 1996) would suggest that a decrease in growth rate was not the sole trigger for differentiation in this organism.

It is also important to emphasize at this point that our findings do not preclude nutrient limitations other than nitrate as being able to elicit differentiation in this organism. Limitation of growth with asparagine was also found to promote spore formation in S. coelicolor (Karandikar et al., 1996). A close link between limitation of certain nitrogenous compounds and differentiation does seem apparent, although in our hands only certain nitrogen sources promoted differentiation.

The data clearly demonstrate that glucose was consumed as the primary carbon source during growth of the organism in solid phase cultures. Furthermore it is apparent that glucose per se did not inhibit the differentiation process in this organism. Interestingly, aerial mycelium formation in a number of streptomycetes has been shown to be prevented when cultured on medium containing glucose (Redshaw et al., 1976; Surowitz \& Pfister, 1985). The mechanism of inhibition is believed to be based upon the subsequent acidification of the medium following glucose metabolism. Although the production of organic acids was detected, the $\mathrm{pH}$ of the cultures did not decrease to levels as low as previously reported in other streptomycetes (Redshaw et al., 1976).
Furthermore, the use of nitrate as a nitrogen source contributed to the resistance of our system to acidification. Consumption of nitrate is associated with a rise in $\mathrm{pH}$ of the surrounding medium and is believed to result from proton uptake (Kristjansson et al., 1978), providing an increased buffering capacity once nitrate had become exhausted and acidification of the medium took place.

The excretion of pyruvate and $\alpha$-ketoglutarate is welldocumented in Streptomyces spp. grown in the presence of a rapidly utilized carbon source such as glucose, including Streptomyces venezuelae (Ahmed et al., 1984), Streptomyces alboniger (Surowitz \& Pfister, 1985), Streptomyces peucetius (Dekleva \& Strohl, 1987) and Streptomyces lividans (Madden et al., 1996). These authors have reported various patterns of acid production. In our system, the apparent switch from pyruvate to $\alpha$-ketoglutarate production had not been previously described in other Streptomyces spp. However, the limited understanding of primary metabolism in this organism makes it difficult to elucidate the control mechanism governing the excretion and utilization of these organic acids.

Investigations concerning changes in macromolecular composition under conditions of nitrogen limitation have been limited (Wanner \& Egli, 1990). In the yeast Saccharomyces cerevisiae during nitrogen deprivation (Johnson et al., 1977), the observation that DNA continues to be accumulated whilst RNA and protein cease accretion, closely correlates with the pattern seen in our organism. In Streptomyces bygroscopicus, Reisenberg \& Bergter (1984) reported a similar effect on RNA and protein accumulation following an induced stringent response. It is likely that a stringent response may result from nitrate exhaustion, henceforth exhibiting a regulatory effect upon both RNA and protein synthesis. The constant accumulation of DNA may indicate the further generation of chromosomes in areas of aerial hyphae destined to form spores. In addition it has been reported that DNA replication continues in aged hyphal compartments of streptomycetes (Kretschmer \& Kummer, 1987), resulting in a cell mass with a high DNA/RNA ratio during the secondary growth phase. Clearly, balanced growth is not a characteristic of the secondary growth phase. However this is not simply due to an adjustment of macromolecular synthesis but also involves the accumulation of storage compounds.

Braña et al. (1986) had previously reported that both trehalose and glycogen accumulated during the secondary growth phase. In contrast to these results, the present study has shown that trehalose accumulation is exclusively associated with the primary growth phase and no temporal correlation between differentiation and trehalose formation can be deduced from these results. McBride \& Ensign (1987a, b) showed trehalose to be an important carbon storage compound in streptomycete spores. Our data suggests that trehalose is not exclusively found in spores, although this does not 
discount that trehalose is sequestered in spores during the differentiation process. Glycogen, on the other hand, appeared to be temporally associated with both the secondary growth phase and differentiation. Interestingly, glycogen degradation occurred during the period when sporulation was observed. These findings correlate with the ultrastructural data presented by Plaskitt \& Chater (1995), who suggest that glycogen synthesis is associated with aerial mycelium formation whilst glycogen degradation coincides with spore maturation. The present study has indicated that glycogen degradation occurred whilst glucose was still present in the medium, suggesting that either the enzymes of glycogen degradation in S. coelicolor are insensitive to catabolite repression or that the site of glycogen catabolism is spatially separated from the medium glucose.

The most abundant compounds produced following nitrate depletion were lipids. In studies of submerged cultures, Packter et al. (1985) suggested that the major lipids synthesized in the secondary phase of growth of $S$. coelicolor are neutral lipids with triacylglycerols as the major components. Furthermore, Olukoshi \& Packter (1994) reported that when Streptomyces lividans cells were transferred to low-nitrogen medium a fourfold increase in triacylglycerol accumulation occurred once nitrogen became limiting. Confirmation that neutral lipid is accumulated in both $S$. lividans and S. coelicolor during the stationary phase was shown by Packter \& Olukoshi (1995) who reported that the lipid component of the cell occupied $80 \%$ of the total cell volume in this phase of growth. It would therefore appear that lipids represent a significant energy reserve compound in these organisms.

Coincident with the depletion of nitrate the surface of the cultures became hydrophobic. The degree of hydrophobicity that we measured was comparable to a previous report on surface cultures of $S$. venezuelae, Streptomyces griseus and Streptomyces viridochromogenes (Bradshaw, 1974). Considerable evidence exists indicating that during aerial mycelium development streptomycetes are able to synthesize hydrophobic sheath layers. These layers have been variously described as being composed of lipid (Erikson, 1947; Kalakoutskii, 1961), chitin (Smucker \& Pfister, 1978), divalent cations (Pozharitskaja et al., 1974, 1976) or protein (Guijarro et al., 1988; Willey et al., 1991). There has been considerable interest in the functional role of hydrophobic cell wall proteins (hydrophobins) which appear to be involved in the formation of aerial growth in fungi (Wessels, 1997). It is tempting to speculate that streptomycetes express similar proteins during the development of aerial growth and indeed the spore-associated proteins described by Willey et al. (1991) may fall into this category. The role of this hydrophobic transition during differentiation in $S$. coelicolor remains to be elucidated. Furthermore, it still needs to established whether the change in physiology following nitrate depletion is intimately linked with the hydrophobic nature of the culture surface and the initiation of aerial growth.

\section{REFERENCES}

Ahmed, Z. U., Shapiro, S. \& Vining, L. C. (1984). Excretion of $\alpha$ keto acids by strains of Streptomyces venezuelae. Can J Microbiol 30, 1014-1021.

Allan, E. J. \& Prosser, J. I. (1985). A kinetic study of the colony growth of Streptomyces coelicolor A3(2) and J802 on solid medium. J Gen Microbiol 131, 2521-2532.

Bradford, M. M. (1976). A rapid and sensitive method for the quantitation of microgram quantities of protein utilizing the principle of protein-dye binding. Anal Biochem 72, 248-254.

Bradshaw, R. M. (1974). Aspects of spore surface structure and chemistry in the Actinomycetales. PhD thesis, University of Liverpool.

Braña, A. F., Manzanal, M. B. \& Hardisson, C. (1982). Characterization of intracellular polysaccharides of Streptomyces. Can J Microbiol 28, 1320-1323.

Braña, A. F., Mendez, C., Diaz, L. A., Manzanal, M. B. \& Hardisson, C. (1986). Glycogen and trehalose accumulation during colony development in Streptomyces antibioticus. J Gen Microbiol 132, 1319-1326.

Champness, W. C. \& Chater, K. F. (1994). Regulation and integration of antibiotic production and morphological differentiation in Streptomyces spp. In Regulation of Bacterial Differentiation, pp. 61-93. Edited by P. J. Piggot, C. P. Moran \& P. Youngmann. Washington, DC: American Society for Microbiology.

Daza, A., Martin, J. F., Dominguez, A. \& Gil, J. (1989). Sporulation of several species of Streptomyces in submerged cultures after nutritional downshift. J Gen Microbiol 135, 2483-2491.

Dekleva, M. L. \& Strohl, W. R. (1987). Glucose-stimulated acidogenesis by Streptomyces peucetius. Can J Microbiol 33, 1129-1132.

Elbein, A. D. (1967). Carbohydrate metabolism in Streptomyces. II. Isolation and enzymic synthesis of trehalose. J Bacteriol 94, $1520-1524$

Ensign, J. C. (1978). Formation, properties and germination of actinomycete spores. Annu Rev Microbiol 32, 185-219.

Erikson, D. (1947). Differentiation of the vegetative and sporogenous phases of the actinomycetes. I. The lipid nature of the outer wall of the aerial mycelium. J Gen Microbiol 1, 39-44.

Folch, J., Lees, M. \& Sloane-Stanley, G. H. (1957). A simple method for the isolation and purification of total lipid from animal tissues. J Biol Chem 226, 497-509.

Glazebrook, M. A., Doull, J. L., Studdard, C. \& Vining, L. C. (1990). Sporulation of Streptomyces venezuelae in submerged cultures. J Gen Microbiol 136, 581-588.

Granozzi, C., Billetta, R., Passantino, R., Sollazzo, M. \& Puglia, A. M. (1990). A breakdown in macromolecular synthesis preceding differentiation in Streptomyces coelicolor A3(2). J Gen Microbiol 136, 713-716.

Guijarro, J. A., Santamaria, R., Schauer, A. \& Losick, R. (1988). Promoter determining the timing and spatial localization of transcription of a cloned Streptomyces coelicolor gene encoding a spore-associated polypeptide. J Bacteriol 170, 1895-1901.

Harder, W. \& Dijkhuizen, L. (1983). Physiological responses to nutrient limitation. Annu Rev Microbiol 37, 1-23.

Hobbs, G., Frazer, C. M., Gardner, D. C. J., Cullum, J. A. \& Oliver, S. G. (1989). Dispersed growth of Streptomyces in liquid culture. Appl Microbiol Biotechnol 31, 272-277.

Hobbs, G., Obanye, A. I. C., Petty, J., Mason, J. C., Barratt, E., 
Gardner, D. C. J., Flett, F., Smith, C. P., Broda, P. \& Oliver, S. G. (1992). An integrated approach to studying regulation of production of the antibiotic methylenomycin by Streptomyces coelicolor. J Bacteriol 174, 1487-1494.

Hodgson, D. A. (1992). Differentiation in actinomycetes. Symp Soc Gen Microbiol 47, 407-440.

Hodgson, D. A. \& Chater, K. F. (1981). A chromosomal locus controlling extracellular agarase production by Streptomyces coelicolor A3(2) and its inactivation by chromosomal integration of plasmid SCP1. J Gen Microbiol 124, 339-348.

Hopwood, D. A. (1959). Linkage and the mechanism of recombination in Streptomyces coelicolor. Ann NY Acad Sci 81, 887-898.

Hopwood, D. A. (1960). Phase-contrast observations on Streptomyces coelicolor. J Gen Microbiol 22, 295-302.

Huber, F. M., Piper, R. L. \& Mertz, F. P. (1987). Sporulation of Streptomyces roseosporus in submerged culture. J Ind Microbiol 2, 235-241.

Johnson, G. C., Singer, R. A. \& McFarlane, E. S. (1977). Growth and cell division during nitrogen starvation of the yeast Saccharomyces cerevisiae. J Bacteriol 132, 723-730.

Kalakoutskii, L. V. (1961). On reflection of plane-polarized light by the surface of aerial mycelium of actinomycetes. Microbiology (English translation of Mikrobiologiya) 30, 409-413.

Kalakoutskii, L. V. \& Agre, N. S. (1976). Comparative aspects of development and differentiation in actinomycetes. Bacteriol Rev 40, 469-524.

Karandikar, A., Sharples, G. P. \& Hobbs, G. (1996). Influence of medium composition on sporulation by Streptomyces coelicolor A3(2) grown on defined media. BioTechniques 10, 79-82.

Kendrick, H. E. \& Ensign, J. C. (1983). Sporulation of Streptomyces griseus in submerged culture. J Bacteriol 155, 357-366.

Koepsel, R. \& Ensign, J. C. (1984). Microcycle sporulation of Streptomyces viridochromogenes. Arch Microbiol 140, 9-14.

Kretschmer, S. \& Kummer, C. (1987). Increase of nucleoid size with increasing age of hyphal region in vegetative mycelia of Streptomyces granaticolor. J Basic Microbiol 27, 23-27.

Kristjansson, J. K., Walter, B. \& Hollocher, T. C. (1978). Respiration-dependent proton translocation and the transport of nitrate and nitrite in Paracoccus denitrificans and other denitrifying bacteria. Biochemistry 17, 5014-5019.

McBride, M. J. \& Ensign, J. C. (1987a). Effects of intracellular trehalose content on Streptomyces griseus spores. J Bacteriol 169, 4995-5001.

McBride, M. J. \& Ensign, J. C. (1987b). Metabolism of endogenous trehalose by Streptomyces griseus spores and by the spores of other actinomycetes. J Bacteriol 169, 5002-5007.

Madden, T., Ward, J. M. \& Ison, A. P. (1996). Organic acid excretion by Streptomyces lividans TK24 during growth on defined carbon and nitrogen sources. Microbiology 142, 31813185.

Monod, J. (1942). Recherches sur la Croissance des Cultures Bacteriennes, 2nd edn. Paris: Hermann.

Olukoshi, E. R. \& Packter, N. M. (1994). Importance of stored triacylglycerols in Streptomyces: possible carbon source for antibiotics. Microbiology 140, 931-943.

Packter, N. M. \& Olukoshi, E. R. (1995). Ultrastructural studies of neutral lipid localisation in Streptomyces. Arch Microbiol 164, $420-427$.

Packter, N. M., Flatman, S. \& Lucock, A. J. (1985). Formation of storage lipids and actinorhodin, a phenolic antibiotic, in Streptomyces coelicolor. Biochem Soc Trans 13, 251-252.

Pirt, S. J. (1975). Principles of Microbe and Cell Cultivation. Oxford: Blackwell Scientific Publications.

Plaskitt, K. A. \& Chater, K. F. (1995). Influences of developmental genes on localised glycogen deposition in colonies of a mycelial prokaryote, Streptomyces coelicolor A3(2): a possible interface between metabolism and morphogenesis. Phil Trans $R$ Soc Lond B 347, 105-121.

Plummer, D. T. (1987). An Introduction to Practical Biochemistry, 3rd edn. London: McGraw-Hill.

Pozharitskaja, L. M., Taptykova, S. D., Sarkisyan, S. T., Tulskii, S. V., Cherny, N. E. \& Kalakoutskii, L. V. (1974). Composition of extracellular tubular structures produced by 'fructose' variant of Actinomyces roseoflavus var. roseofungini. Antibiotika 19, 963966.

Pozharitskaja, L. M., Taptykova, S. D., Cherny, N. E., Tulskii, S. V., Lebedev, V. I. \& Kalakoutskii, L. V. (1976). Composition of tubular structures obtained from parent strain of Actinomyces roseoflavus var. roseofungini. Antibiotika 21, 787-791.

Preiss, J. \& Romeo, T. (1989). Physiology, biochemistry and genetics of bacterial glycogen synthesis. Adv Microb Physiol 30, 183-238.

Ranade, N. \& Vining, L. C. (1992). Accumulation of intracellular carbon reserves in relation to chloramphenicol biosynthesis by Streptomyces venezuelae. Can J Microbiol 39, 377-383.

Redshaw, P. A., McCann, P. A., Sankaran, L. \& Pogell, B. M. (1976). Control of differentiation in streptomycetes: involvement of extrachromosomal deoxyribonucleic acid and glucose repression in aerial mycelium development. J Bacteriol 125, 698-705.

Reisenberg, D. \& Bergter, F. (1984). Establishment of a system suitable for analysis of balanced and unbalanced growth of Streptomyces hygroscopicus. J Gen Microbiol 130, 2543-2548.

Ruddick, S. M. \& Williams, S. T. (1972). Studies on the ecology of actinomycetes in soil. V. Some factors influencing the dispersal and adsorption of spores in soil. Soil Biol Biochem 4, 93-103.

Shahab, N., Kamarrudin, K., Platt, J., Butler, P. R., Oliver, S. G. \& Hobbs, G. (1994). Cell physiology and antibiotic production of Streptomyces coelicolor grown on solid medium. Biotechnol Lett 16, 1015-1020.

Shahab, N., Flett, F., Oliver, S. G. \& Butler, P. R. (1996). Growth rate control of protein and nucleic acid content in Streptomyces coelicolor A3(2) and Escherichia coli B/r. Microbiology 142, 1927-1935.

Smit, G., Sraver, M. H., Lugtenberg, B. J. J. \& Kijne, J. W. (1992). Flocculance of Saccharomyces cerevisiae cells induced by nutrient limitation, with cell surface hydrophobicity as a major determinant. Appl Environ Microbiol 58, 3709-3714.

Smucker, R. A. \& Pfister, R. M. (1978). Characteristics of Streptomyces coelicolor A3(2) aerial spore rodlet mosaic. Can J Microbiol 24, 397-408.

Surowitz, K. G. \& Pfister, R. M. (1985). Glucose metabolism and pyruvate excretion by Streptomyces alboniger. Can J Microbiol 31, 702-706.

Wanner, U. \& Egli, T. (1990). Dynamics of microbial growth and cell composition in batch culture. FEMS Microbiol Rev 75, 19-44.

Wessels, J. G. H. (1997). Hydrophobins: proteins that change the nature of the fungal surface. Adv Microbiol Physiol 38, 1-45.

Wessels, J. G. H., de Vries, O. M. H., Ásgeirsdóttir, S.A. \& 
Schuren, F. H. J. (1991). Hydrophobin genes involved in formation of aerial hyphae and fruiting bodies in Schizophyllum commune. Plant Cell 3, 793-799.

Willey, J., Santamaria, R., Guijarro, J., Geistlich, M. \& Losick, R.

(1991). Extracellular complementation of a developmental mu- tation implicates a small sporulation protein in aerial mycelium formation by Streptomyces coelicolor. Cell 65, 641-650.

Received 6 May 1997; revised 22 July 1997; accepted 30 July 1997. 